\title{
UMA REFLEXÃO SOBRE A CONCEPÇÃO FREIRIANA PRESENTE NOS TRABALHOS APRESENTADOS NO SIMPÓSIO NACIONAL DE ENSINO DE FÍSICA
}

\author{
Afonso Werner da Rosa ${ }^{1}$ \\ Alisson Cristian Giacomelli ${ }^{2}$ \\ Cleci Teresinha Werner da Rosa ${ }^{3}$
}

\begin{abstract}
Resumo: $O$ presente trabalho teve como objetivo estudar a presença da concepção freiriana no ensino de Física por meio da análise de trabalhos apresentados no Simpósio Nacional de Ensino de Física. $\mathrm{O}$ aspecto central esteve atrelado a identificar características desses trabalhos em termos de autores, instituiçóes, abordagem de pesquisa, nível de escolarização, focos temáticos e presença dos conceitos freirianos. A pesquisa desenvolvida foi de abordagem qualitativa, do tipo "estado do conhecimento" envolvendo um corpus de doze estudos identificados a partir do uso do descritor "Freire" e da leitura dos trabalhos. Como resultado aponta-se que o foco está na utilizaçáo dos Três Momentos Pedagógicos associados a intervençôes didáticas e ainda que: há autores consagrados nessas investigaçôes; a educação básica tem sido o nível de escolarização privilegiado nos estudos; o currículo e a formação de professores concentram parte significativa das investigaçóes; e, os conceitos feirianos de comunidade, diálogo e autonomia se fazem presente, porém em proporcionalidades distintas.
\end{abstract}

Palavras-chave: estado do conhecimento; concepção freiriana; pesquisa.

1 Graduando em Física-L na Universidade de Passo Fundo, RS e bolsista voluntário de Iniciação Científica - PIVIC UPF.

2 Doutorando em Educação na Universidade de Passo Fundo, professor do curso de Física-L na Universidade de Passo Fundo.

3 Doutora em Educação Científica e Tecnológica pela Universidade Federal de Santa Catarina, docente do Programa de Pós-Graduação em Educação e do Programa de Pós-Graduação em Ensino de Ciências e Matemática, ambos na Universidade de Passo Fundo. 


\title{
A REFLEXION ABOUT THE FREIRIAN CONCEPT PRESENT ON STUDIES FROM THE NATIONAL SYMPOSIUM OF PHYSICS EDUCATION
}

\begin{abstract}
The current project had the goal to study the Freirian concept presence in Physics teaching analyzing the studies that were presented on the National Symposium of Physics Education. The central aspect was tied to identifying features of these studies in term of authors, institutions, research approach, schooling level, thematic focus and the presence of the Freirian concept. The developed research was qualitative and "state of knowledge" kind and involves a corpus of twelve identified studies as of "Freire" descriptor and the analysis of the essays. As result, the focus is in the use of the Three Pedagogical Moments associated with the didactic interventions and although: there are consecrated authors in the investigations; the basic education has been the schooling level that were privileged in the studies; the curriculum and the teachers training are focused on the meaningful part of the investigations; and the Freirian concepts of community, dialogue and autonomy are present, although in distinct proportionalities.
\end{abstract}

Keyword: State of knowledge; Freirian concept; research.

\section{Introduçáo}

A associação de Paulo Freire com o ensino de Física remonta à década de 1980 com as publicações de Demétrio Delizoicov e de José André Angotti, em 1982. Nelas os autores constroem uma aproximação da obra de Freire com o campo da Educação em Ciências e, a partir disso, com o ensino de Física. Tais estudos se dedicam a "promover a transposição da concepção de educação de Paulo Freire para o espaço da educação formal" (MUENCHEN, 2010, p. 15).

A forma encontrada por eles está representada no que especificam como "Momentos Pedagógicos", mais tarde denominados de "Três Momentos Pedagógicos" (3MP). Delizoicov e Angotti (1990; 1991), nessa perspectiva, descrevem etapas - momentos - que devem nortear a estruturação de um currículo ou um planejamento de aula, envolvendo a problematização, a discussão dos conhecimentos e a aplicação desses na busca da solução ao problema inicial. Essa compreensão, que será detalhada mais adiante, é utilizada por pesquisadores da área do ensino de Física como sinônimo da pedagogia freiriana, como apontado por Gehlen, Machado e Auth (2009). Ela, entretanto, não representa a única possibilidade de trazer essa concepção pedagógica à sala de aula, uma vez que parte dos estudos que associam Paulo Freire ao campo educacional, estão vinculados aos processos de alfabetização e a centralização do educando no processo de aprendizagem.

Resulta disto a problemática central deste estudo, que pretende analisar como o campo do ensino de Física se serve da obra de Paulo Freire, mapeando pesquisas desenvolvidas na área. $\mathrm{O}$ intuito não está em evidenciar a presença de alguma abordagem didática, tampouco de dogmatizar os estudos relacionados aos $3 \mathrm{MP}$, mas analisar o impacto da pedagogia freiriana no campo em investigação. Esse entendimento infere, como questão de pesquisa, a seguinte pergunta: No 
contexto da educação brasileira, como são caracterizados os estudos e articulados os conceitos da pedagogia freiriana com o ensino de Física?

O questionamento central se justifica pelas indiscutíveis contribuições de Paulo Freire à educação brasileira, a exemplo de outros países do mundo. Sua obra foi adotada como referência pelos movimentos envolvidos com a educação popular no país, caracterizando-se pela ênfase nas práticas cotidianas e defesa da conscientização no processo educativo, como busca da construção de uma sociedade mais justa e igualitária.

Esses aspectos conferem à obra freiriana legitimidade e importância no ensino dos mais diferentes componentes curriculares, dentre os quais está a Física. Analisar a obra de Paulo Freire, a partir desse campo do conhecimento, representa uma oportunidade de resgatar os conceitos centrais dessa pedagogia e verificar perspectivas de sua utilização como referencial educacional para o ensino de Física. Essa possibilidade se revela, na atual conjuntura conturbada do cenário político brasileiro, como alternativa para manter ativo o debate entorno dos objetivos da educação escolarizada e sobre a quem interessa esse tipo de ensino no país.

Soma-se ao exposto, a justificativa de que Gehlen, Machado e Auth (2009) realizaram estudo que evidenciou a presença de Paulo Freire nos trabalhos apresentados no Simpósio Nacional de Ensino de Física (SNEF) no período de 2003 a 2007. Nesse estudo, os autores observaram que, dentre 1.128 trabalhos apresentados nas edições do SNEF, 56 deles tinham como referência as obras de Freire, o que corresponde à cerca de $4,2 \%$ do total de trabalhos publicados. Outro estudo que proporcionou uma reflexão sobre a forma como a obra de Paulo Freire é utilizada no ensino de Física foi o de Lôbo e Golvêa (2017). O levantamento dos autores envolveu o período compreendido entre a primeira edição SNEF (1970) à vigésima primeira edição do seminário (2013) e analisou 40 relatos de estudos. Desses, segundo os autores:

18 utilizam a prática freireana, partindo da realidade concreta dos educandos, enquanto os outros 22 apresentam as ideias e metodologia freireanas, mas a prática apresentada segue por outro caminho (p. 6).

Os estudos supracitados corroboram com a tese de que a obra de Freire subsidia pesquisas no ensino de Física, apresentando incremento a partir da presença da concepção freiriana de ensino em documentos oficiais e correlatos, a partir dos anos de 2000. Frente a essa realidade e aos estudos mencionados, o presente trabalho tem por objetivo analisar a produção nacional sobre o ensino de Física identificada nos relatos de estudos apresentados no SNEF, analisando o modo como estão articulados com os conceitos presentes na obra de Paulo Freire.

\section{Referencial teórico}

Paulo Reglus Neves Freire, ou apenas Paulo Freire, é um dos maiores educadores brasileiros, considerado patrono da educação brasileira desde 2014. Nascido no dia 19 de setembro de 1921, na cidade de Recife, PE, aprendeu a ler 
as palavras orientado pela Mãe Edeltrudes Neves Freire e aos 22 anos, em 1943, ingressou na Faculdade de Direito do Recife. Em 1959 tornou-se doutor pela Universidade de Recife e em 1961 foi empossado professor titular nas disciplinas de Filosofia e História da Educação na mesma instituição. Suas obras sustentam a necessidade de uma educação crítica, humanizada e libertadora, como é possível observar, mais diretamente, no livro Pedagogia do Oprimido (1968) o qual é base para a construção deste referencial teórico. Essa visão também está presente em outros trabalhos de sua autoria, dos quais se destacam as obras Pedagogia da Autonomia e Pedagogia da Esperança, pois, a exemplo do escrito abordado neste texto, tais obras têm igual importância na compreensão da pedagogia freiriana.

Antes da discussão a respeito da obra base deste referencial, é pertinente a análise do contexto social e político no qual foi escrita. A educação brasileira, à época, encontrava-se mergulhada no tecnicismo, sendo vista apenas com a finalidade de qualificar a mão de obra oferecida ao mercado de trabalho. Além disso, influenciada pelo positivismo de Augusto Comte, o modelo educacional vigente não incentivava a crítica no educando, sendo fortemente constituída de visões dogmáticas ${ }^{4}$. A obra foi escrita enquanto Freire estava exilado no Chile devido à ditadura militar instaurada no Brasil, sendo publicada no país somente em 1974, dois anos após a publicação do livro em Portugal. O livro é inspirado nas reflexões do educador durante o período citado e influenciado pelas ideias de pensadores como Karl Marx, Georg Friedrich Hegel, Jean-Paul Sartre, Simone de Beauvoir entre outros. Talvez a maior influência, dentre tantos pensamentos, seja a concepção de dialética em Marx e Hegel ${ }^{5}$, a qual inspira a concepção dialógica da educação defendida por Freire. Além disso, as relações opressor-oprimido também são fortemente estruturadas nas concepções hegelianas ${ }^{6}$.

A obra traz direcionamento para diversos questionamentos ao longo da leitura e, como todo bom questionamento, começa pela justificativa. Essa, por sua vez, surge para Freire a partir da observação da relação opressor-oprimido, na qual, o opressor é detentor dos meios de produção e, por consequência, ocupa as mais altas classes sociais. Os oprimidos, por sua vez, ocupam as demais camadas da sociedade, considerados, quase que totalmente, dependentes das ações dos opressores. Estando nessa posição, o opressor assume o papel de colonizador perante o oprimido, o colonizado. Como colonizador, o opressor instaura no oprimido suas perspectivas, induz, no indivíduo, um desejo de ascensão social que desperta, no oprimido, a aspiração de se tornar o opressor. Claro que quando se

4 Faz-se referência ao dogmatismo em Immanuel Kant, ou seja, o proceder dogmático da razão pura, sem a crítica de sua própria capacidade.

5 Mesmo levando em consideração as claras diferenças entre as duas concepções dialéticas, podese identificá-las nas concepções freirianas.

6 Detecta-se aqui a obra Fenomenologia do Espírito (1807), mais especificamente o trecho "Independência e dependência da Consciência-de-si: Dominação e escravidão". 
trata nesse desejo, refere-se a algo presente no inconsciente do oprimido, um desejo involuntário.

Salvo escassas exceções, esse desejo é meramente ilusão, visto que, a ascensão social necessária é um feito intangível aos oprimidos, enquanto estiverem sob o domínio dos colonizadores. Também é possível traçar diversos paralelos com a relação de dominação e escravidão na independência e dependência da consciênciade-si em Hegel. Para ele (1992, p. 126): "A consciência-de-si é em si e para si quando e porque é em si para si para uma Outra". O educando, então, só se faz humanizado ${ }^{7}$ quando reconhecido como sujeito ativo de sua história, quando reconhecidas suas ambições e anseios, quando reconhecido o Ser Humano por traz do aluno. Para Freire, quando não ocorre o reconhecimento do educando como ser autêntico, o esse não se torna livre e passa a ser objeto da história. Ainda na Dominação e Escravidão (HEGEL, 1992, p. 130) depara-se com a seguinte situação: "Uma pura consciência-de-si, e uma consciência que não é puramente para si, mas para um outro, isto é, como consciência essente, ou consciência na figura da coisidade".

Ainda no pensamento hegeliano, Novelli (2001, p. 69) mostra que: "A realidade é processo do vir a ser, isto é, não é dada, mas vem a ser e, isso, constantemente. Se a realidade está sempre vindo a ser é porque ela nunca é definitivamente". A partir disso, Freire observa a maneira com que professores apresentam a realidade aos alunos e traz a ideia de educação bancária como um modelo dogmático e unilateral do processo de aprendizagem. Nessa concepção o autor retrata o professor como detentor do conhecimento, fonte do conhecimento ou aquele que sabe, e, nessa posição, o educador dita a realidade como algo estático, constante e sem a possibilidade da práxis. A partir disso, o professor, num ato de doação, entrega saberes prontos aos educandos, seres que nada sabem, "vasilhas, em recipientes a serem enchidos pelo educador" (FREIRE, 2014 p. 80). Segue o autor, mencionando que a transferência de conhecimento do professor ao aluno é análoga a um depósito bancário, no qual o educador, em posse do conhecimento, o deposita no aluno, onde esse fica guardado até ser solicitado mediante um teste ou avaliação (FREIRE, 2014). Os educandos, assim, são tratados como objetos do processo de aprendizagem, não tendo sua consciência-de-si reconhecida perante outra, uma figura da coisidade. Resume-se essa concepção com o seguinte trecho da obra de Freire (2014, p. 81):

Educador e educandos se arquivam na medida em que, nesta distorcida visão de educação, não há criatividade, não há transformação, não há saber. Só existe saber na invenção, na reinvenção, na busca inquieta, impaciente, permanente, que os homens fazem no mundo, com o mundo e com os outros.

7 Em Johann Gottfried von Herder (1774-1803) há a concepção de educação como mencionado por Novelli (2001, p.68): "Herder também considera a educação de forma singular, pois ela é a possibilidade de superação e melhoria da condição humana marcada por carências e limitações. O fim de toda e qualquer ciência é humanizar, isto é, promover o homem de sua condição humana menor para a maior". 
Para contrapor a concepção bancária da educação, Freire apresenta a discussão de uma educação crítica e humanizadora. Nela, o educando se torna o protagonista do seu processo de aprendizagem, levando consigo toda a sua experiência de vida, suas perspectivas e sua visão de mundo, para, então, aprender a se tornar sujeito de sua própria história. O educando aprende a ser gente tornando-se ciente de si e de seu papel como Ser, assim, ele faz-se para si.

Freire propõe os chamados temas geradores, uma metodologia que visa aproximar o mundo vivenciado pelos estudantes à sala de aula. Os temas geradores buscam, num primeiro momento, estudar a realidade dos alunos da escola para que, a partir disso, seja possível encontrar problemas ou contradições que basearão os momentos seguintes. Iniciam-se, após o estudo da realidade, investigações dentro do tema seguindo as etapas de codificação-problematização-descodificação. A codificação consiste, segundo o autor, na "representação de uma situação existencial" (FREIRE, 2014, p. 136). Identificada a situação codificada, começa a problematização, partindo da observação das fragilidades e incoerências, surge a necessidade da apreensão de novos conceitos, esses servirão para a descodificação da situação representada.

Para alcançar essa educação crítica e humanizadora, e pôr em prática os temas geradores, o diálogo é o caminho a ser seguido. Em seus dois últimos capítulos, a obra de Freire (2014) discorre a respeito das ações dialógicas ${ }^{8}$ e não dialógicas da educação, considerando o diálogo como prática crítica e libertadora e, por conseguinte, a falta do desse como prática sectária. $\mathrm{O}$ autor mostra a necessidade da dialogicidade ${ }^{9}$ da educação. O diálogo é tido como fenômeno humano e a palavra é o meio pelo qual ele se constrói, mas a palavra não pode ser tratada apenas dessa maneira. Uma rápida análise da palavra revela seus dois lados, de um a ação enunciada por ela, de outro a reflexão, nessa interação - denominada "práxis" - se faz de tal maneira que, para o autor: "Não há palavra verdadeira que não seja práxis. Daí que dizer a palavra verdadeira seja transformar o mundo" (FREIRE, 2014 p. 107). O diálogo permite ao educando fazer-se parte do mundo, a pronúncia da palavra verdadeira torna-o humanizado, pois, "Existir, humanamente, é pronunciar o mundo, é modificá-lo. O mundo pronunciado, por sua vez, se volta problematizado aos sujeitos pronunciantes, a exigir deles novo pronunciar". O pronunciar das palavras, logo, torna o ser, antes tido como ser menos, ser mais. A educação dialógica leva aos educandos a possibilidade da transformação ao mostrar que o mundo não é estático, ele é pronunciado e, aqueles que o pronunciam têm o poder de modificálo. Para pronunciar o mundo é necessário, primeiro, amá-lo, pois sem amor ao mundo e aos homens não há possibilidade de pronunciá-los. O diálogo também necessita da humildade com os homens cujo mundo pronunciam, a humildade de compreender-se e compreendê-los como seres frutos de suas ambições e

8 Dentre elas os temas geradores

9 Podemos encontrar maiores reflexões a respeito da dialogicidade da educação na obra "Educação como prática da Liberdade". 
complexidades humanas, a humildade de compreender sua incompletude como ser. Segue o autor mencionando que:

Como posso dialogar, se alieno a ignorância, isto é, se a vejo sempre no outro, nunca em mim? Como posso dialogar, se me admito como um homem diferente, virtuoso por herança, diante dos outros, meros 'isto', em quem não reconheço outros eu? (FREIRE, 2014, p. 111).

Em outras palavras, como posso querer humanizar outros homens se não os vejo como humanos, como outros seres iguais a mim? Esse questionamento reflexivo, expresso ao final da obra, é o de que os educadores precisam sempre se reinventar, essa reinvenção por sua vez se faz na crítica, na reflexão e no constante ato de se humanizar, porquanto, uma vez que cientes de si e de se incompletude, há o poder de pronunciar o mundo e fazer com que outros o pronunciem também. Ato este que culmina nos oprimidos, na recuperação da humanidade antes tomada pelos opressores e, por fim, na recuperação da humanidade perdida nos próprios opressores (FREIRE, 2014).

Ao transpor a reflexão contemplada anteriormente para o campo da Educação em Ciências, têm-se nas obras de Demétrio Delizoicov e colaboradores, um importante referencial. Seus estudos possibilitam compreender as contribuições de Paulo Freire para uma concepção dialética do processo de ensino e aprendizagem em Ciências.

A obra inicial a qual foi chamada à atenção é a dissertação de mestrado de Delizoicov (1982) denominada Concepscão problematizadora do ensino de ciências na educação formal que, dentro de um ineditismo, analisa sob um olhar na perspectiva freiriana, a Educação em Ciências. Pode-se destacar, além dessa, sua tese de doutorado denominada Conhecimentos, tensões e transições (DELIZOICOV, 1991) na qual, fundamentado na epistemologia paradigmática de Kuhn e no cognitivismo construtivista de Piaget, o autor dá um novo olhar à pedagogia freiriana, ainda no âmbito da Educação em Ciências. Nela, é apresentada a metodologia dos Momentos Pedagógicos (MP), embasada no processo de codificação-problematizaçãodescodificação dos temas geradores. Os MP, originalmente, consistem na dinâmica de estudo da realidade - estudo científico - e aplicação do Conhecimento (DELIZOICOV, 1991). Inicialmente, o estudo da realidade versa em identificar a situação codificada e analisá-la, identificados os problemas e incoerências no estudo da realidade, inicia-se o estudo do científico. Nessa etapa, buscam-se subsídios bibliográficos para a obtenção dos conhecimentos necessários à resolução dos problemas encontrados. Essa busca é estimulada pelos obstáculos encontrados no estudo da realidade. Por fim, o conhecimento recém adquirido é transposto para uma nova situação, ressaltando as conjecturas do novo conhecimento.

Posteriormente, em Delizoicov e Angotti (1992), tem-se a reformulação dos momentos pedagógicos agora chamados de Três Momentos Pedagógicos (3MP). Ambos consistem, basicamente, na metodologia citada, porém, nessa última versão, existe a dinâmica ordenada como Problematização-Organizạạão do ConhecimentoAplicação do Conhecimento. Na mesma obra, os autores apresentam subsídios ao ensino 
de Ciências, fornecendo sugestões temáticas, assim como referências bibliográficas dentro dos temas abordados.

Parte-se, a partir dessa identificação, à análise da utilização do referencial freiriano como suporte ao ensino de Física, na voz dos estudos publicados no Simpósio Nacional de Ensino de Física.

\section{Metodologia}

A pesquisa realizada é de abordagem qualitativa, considerando que investigar o contexto educacional requer esforço e cuidado, de modo a respeitar as especificidades inerentes a este espaço e aos sujeitos neles presentes, segundo (BOGDAN; BIKLEN, 1994). No entendimento de Triviños (1994), essa abordagem é a mais indicada para pesquisas educativas, pois se deseja priorizar a interpretação e a discussão dos dados de forma a buscar seu significado, a partir da percepção do fenômeno dentro do seu contexto. Continua o autor, relatando que esse tipo de pesquisa procura captar não só a aparência do fenômeno, mas também suas essências, visando explicar sua origem, relações, mudanças e tentando prever possíveis consequências.

Em termos da natureza, o estudo se caracteriza como bibliográfico, uma vez que toma como objeto de análise materiais já publicados. Para isso, segundo Gil (2010), a pesquisa deve passar por determinadas etapas, por exemplo: a natureza do problema; o nível dos conhecimentos que o pesquisador dispõe sobre o assunto; e, o grau de precisão que se pretende conferir à pesquisa.

Identifica-se, portanto, o estudo como uma investigação do tipo estado do conhecimento que, de acordo com Romanowski e Ens (2006), refere-se àqueles que buscam abordar "apenas um setor das publicações sobre o tema estudado" (p. 40). As autoras ainda mencionam que esse tipo de pesquisa busca mapear e discutir uma certa produção acadêmica:

tentando responder que aspectos e dimensões vêm sendo destacados e privilegiados em diferentes épocas e lugares, de que formas e em que condições têm sido produzidas certas dissertações de mestrados e teses de doutorado, publicações em periódicos e comunicações em anais de congressos e seminários (p. 46).

Partindo dessas caracterizações, tem-se como locus para produção de dados o SNEF, evento organizado pela Sociedade Brasileira de Física (SBF) e que agrega pesquisas vinculadas ao ensino de Física. A seleção do evento decorre de sua expressividade nacional, porque pode ser considerado como o de maior relevância e pelo significativo número de trabalhos apresentados e a tradição na área. $O$ recorte fica por conta do período de 2009-2017, dado que, como mencionado na introdução, o trabalho de Gehlen, Machado e Auth (2009) mapeou os eventos anteriores. 
O evento que é bienal, tem seus trabalhos disponibilizados para livre acesso no site da $\mathrm{SBF}^{10}$, podendo ser pesquisado com a utilização de palavras-chaves ou descritores. Nesse sentido, projeta-se a utilização de único descritor: "Freire". A opção está vinculada à possibilidade identificar todos os estudos que utilizam esse referencial e, após a leitura dos trabalhos, selecionar os que empregam esse autor como referencial teórico.

Com o uso do descrito "Freire" foi obtido um conjunto de 18 artigos dos quais quatro foram descartados após análise, já que não se tratam de pesquisa relacionada à obra de Paulo Freire. Os 12 restantes foram analisados e constituíram o corpus de análise deste trabalho. Para tanto, e considerando a leitura dos trabalhos, traçam-se categorias que permitem identificar características nas produções.

\section{Resultados e discussóes}

Os resultados associados às respectivas discussões estão expressos em categorias que buscam responder ao questionamento central do estudo: No contexto da educação brasileira, como são caracterizados os estudos e articulados os conceitos da pedagogia freiriana com o ensino de Física?

\section{a) Relação dos trabalhos selecionados}

Os trabalhos identificados nas edições do Simpósio Nacional de Ensino de Física no período de 2009-2017 estão indicados no quadro 1 a seguir:

Quadro 1 - Relação de trabalhos encontrados nos anais do SNEF

\begin{tabular}{|c|l|l|}
\hline $\begin{array}{c}\text { Edição } \\
\text { (ano) }\end{array}$ & \multicolumn{1}{|c|}{ Trabalho - Título } & \multicolumn{1}{c|}{ Autor(es) } \\
\hline \multirow{2}{*}{$\begin{array}{c}\text { XVIII } \\
(2009)\end{array}$} & $\begin{array}{l}\text { T1 - Freire e Vygotsky no Simpósio } \\
\text { Nacional de Ensino de Física }\end{array}$ & $\begin{array}{l}\text { Simoni Tormöhlen Gehlen;Aniara } \\
\text { Machado; Milton Antonio Auth } \\
\text { ensino de Física: a cosmologia como tema } \\
\text { motivador }\end{array}$ \\
\hline XX & $\begin{array}{l}\text { T3 - A problematização freireana no } \\
\text { contexto do ensino de ciências por } \\
\text { investigação: contribuições para o ensino } \\
\text { de física nos anos iniciais }\end{array}$ & $\begin{array}{l}\text { Ana Paula Solino; Polliane Santos de } \\
\text { Sousa; Simoni Tormöhlen Gehlen }\end{array}$ \\
\hline
\end{tabular}

10 www.sbfisica.org.br 


\begin{tabular}{|c|c|c|}
\hline $\begin{array}{l}\text { Edição } \\
\text { (ano) }\end{array}$ & Trabalho - Título & Autor(es) \\
\hline \multirow{4}{*}{$\begin{array}{c}\text { XXI } \\
(2015)\end{array}$} & $\begin{array}{l}\text { T4 - Abordagem temática freireana no } \\
\text { ensino de Ciências/Física: uma experiência } \\
\text { no Estágio Supervisionado em Física }\end{array}$ & $\begin{array}{l}\text { Polliane Santos de Sousa; Luiz Henrique } \\
\text { da Silva Santo; Yasmin Alves dos Reis; } \\
\text { Simoni Tormohlen Gehlen }\end{array}$ \\
\hline & $\begin{array}{l}\text { T5 - Os usos do celular: uma proposta } \\
\text { de abordagem temática na perspectiva } \\
\text { freireana }\end{array}$ & $\begin{array}{l}\text { Marcia Tiemi Saito; Kathia Schaffer } \\
\text { Gimenes; Rodrigo Correia da Silva; } \\
\text { Ismael de Oliveira Ramos; Ivã Gurgel }\end{array}$ \\
\hline & $\begin{array}{l}\text { T6 - A organização de atividades didático- } \\
\text { pedagógicas de Ciências baseada no tema } \\
\text { gerador: "o perigo do rio água preta em } \\
\text { pau Brasil/BA" }\end{array}$ & $\begin{array}{l}\text { Roger Magalhães da Silva; Polliane } \\
\text { Santos de Sousa; Edcleide da Silva } \\
\text { Pereira Novais; Kamilla Nunes Fonseca; } \\
\text { Simoni Tormohlen Gehlen }\end{array}$ \\
\hline & $\begin{array}{l}\text { T7 - Quem está no Centro? Um confronto } \\
\text { epistemológico entre as visões de mundo } \\
\text { geocêntrica e heliocêntrica }\end{array}$ & $\begin{array}{l}\text { Renan Milnitsky; Yuri Machado; Ivã } \\
\text { Gurgel }\end{array}$ \\
\hline \multirow{5}{*}{$\begin{array}{l}\text { XXII } \\
(2017)\end{array}$} & $\begin{array}{l}\text { T8 - Paulo Freire e ensino de Física: o } \\
\text { caráter freireano dos relatos de experiência } \\
\text { apresentados do I ao XXI SNEF }\end{array}$ & Igor Lôbo; Guaracira Gouvêa \\
\hline & $\begin{array}{l}\text { T9 - Problematizando o aquecimento } \\
\text { global: análise da apropriação de ideias } \\
\text { freireanas de educação por professores }\end{array}$ & $\begin{array}{l}\text { Leandro Oliveira; Ivã Gurgel; Giselle } \\
\text { Watanabe }\end{array}$ \\
\hline & $\begin{array}{l}\text { T10 - Relações Freire-CTS: a Física e o } \\
\text { rompimento da cultura do silêncio }\end{array}$ & $\begin{array}{l}\text { Júlio César Lemos Milli, Eliane dos } \\
\text { Santos Almeida, Kamilla Nunes } \\
\text { Fonseca, Hiago Luiz Nascimento Silva, } \\
\text { Maic Brito Silva, Simoni Tormohlen } \\
\text { Gehlen }\end{array}$ \\
\hline & $\begin{array}{l}\text { T11 - Contribuições da Física para a } \\
\text { conservação da carne vendida na feira do } \\
\text { bairro de Fátima em Itabuna/BA }\end{array}$ & $\begin{array}{l}\text { Kamilla Nunes Fonseca; Júlio Cesar } \\
\text { Lemos Milli; Manuela Gomes Bomfim; } \\
\text { Eliane dos Santos Almeida } \\
\text { Cleilde Aguiar Neres; Simoni Tormohlen } \\
\text { Gehlen }\end{array}$ \\
\hline & $\begin{array}{l}\text { T12 - Os momentos pedagógicos e a } \\
\text { análise textual discursiva na abordagem } \\
\text { do conceito de trocas de calor com } \\
\text { professores de ciências }\end{array}$ & $\begin{array}{l}\text { Júlio César Lemos Milli; Manuela Gomes } \\
\text { Bomfim; Kamilla Nunes Fonseca; } \\
\text { Cleilde Aguiar Neres; Maria Angelica } \\
\text { Motta Dórea; Hiago Luiz Nascimento } \\
\text { Silva; Simoni Tormohlen Gehlen }\end{array}$ \\
\hline
\end{tabular}

Fonte: autores, 2019.

O expresso no quadro possibilita identificar um aumento no número de trabalhos apresentados no evento, o que está em acordo com a ampliação da produção nacional na área da pesquisa em ensino de Física. Além disso, pode-se relacionar o aumento no interesse pela temática freiriana a partir da publicação dos Parâmetros Curriculares Nacionais (PCN's) em 1999 que apresentou, em suas concepções, alinhamento com a perspectiva de Paulo Freire na educação. 


\section{b) Distribuição por instituições}

O quadro 2 ilustra a distribuição dos trabalhos por instituições de origem dos autores.

Quadro 2 - Distribuição dos trabalhos por regiões e instituições.

\begin{tabular}{|c|l|}
\hline Trabalho (s) & \multicolumn{1}{c|}{ Instituição } \\
\hline T1 & $\begin{array}{l}\text { Universidade Federal de Santa Catarina } \\
\text { Universidade Noroeste do Rio Grande do Sul }\end{array}$ \\
\hline T2 & Universidade de São Paulo \\
\hline T3 & $\begin{array}{l}\text { Universidade Estadual do Sudoeste da Bahia } \\
\text { Universidade Estadual de Santa Cruz - Ilhéus }\end{array}$ \\
\hline T4 & Universidade Estadual de Santa Cruz - Ilhéus \\
\hline T5 & Universidade de São Paulo \\
\hline T6 & Universidade Estadual do Sudoeste da Bahia \\
\hline T7 & Universidade de São Paulo \\
\hline T8 & Universidade Federal do Estado do Rio de Janeiro \\
\hline T9 & Universidade de São Paulo \\
\hline T10 & Universidade Estadual de Santa Cruz - Ilhéus \\
\hline T11 & Universidade Estadual de Santa Cruz - Ilhéus \\
\hline T12 & Universidade Estadual de Santa Cruz - Ilhéus \\
\hline
\end{tabular}

Fonte: autores, 2019.

Do apresentado no quadro, tem-se a identificação de dois focos de pesquisa no Brasil: um localizado em São Paulo (SP) - Universidade de São Paulo (USP) e outro na Bahia, envolvendo duas instituições - Universidade Estadual do Sudoeste da Bahia (UESB) e Universidade Estadual de Santa Cruz (UESC), Ilhéus (BA). Vale registrar que para os trabalhos localizados na Bahia, assim como o da Universidade Federal de Santa Catarina (UFSC), há em comum a presença de uma mesma autora que assina seis dos 12 trabalhados analisados neste texto.

\section{c) Tipo de estudo investigativo e nivel de escolarização envolvido.}

Em relação ao nível de escolarização existem: dois cursos de formação com professores dos anos iniciais (T3 e T11), três cursos de formação com professores do ensino fundamental II (T6, T10 e T12), três atividades desenvolvidas por licenciandos de Física no ensino médio (T4, T5 e T7) e um trabalho de formação de professores, cujo nível de atuação de todos profissionais participantes não foi identificado, apenas o de alguns (T9). Além disso, há dois trabalhos estruturados na revisão de estudos publicados que se apropriam de conceitos freirianos, os quais fundamentam a pesquisa aqui expressa (T1 e T8), e um trabalho que sugere o uso de temas geradores no ensino médio e superior (T2). 
Do exposto é possível observar uma tendência em apresentar trabalhos relacionados às propostas didáticas e voltados à educação básica, especialmente ao Ensino Fundamental - Anos Finais e Ensino Médio.

\section{d) Foco temático da publicaşão}

Gehlen, Machado e Auth (2009) apresenta os focos temáticos predominantes nas pesquisas envolvendo o referencial freiriano, trabalho considerado o ponto de partida para o presente estudo. Utiliza-se essa categorização como referencial à discussão dos focos temáticos, conforme apresentado no quadro 3.

Quadro 3 - Distribuição dos estudos por foco temático.

\begin{tabular}{|l|c|}
\hline \multicolumn{1}{|c|}{ Categoria- Foco temático } & Trabalho \\
\hline Materiais e métodos de ensino & T9 \\
\hline Currículo e organização do conhecimento & T3, T5, T6 \\
\hline Formação continuada de professores & T4, T11, T12 \\
\hline História, Filosofia e Sociologia da ciência & T2, T7 \\
\hline Abordagem CTS & T10 \\
\hline Pesquisa do tipo “estado da arte” & T1, T8 \\
\hline
\end{tabular}

Fonte: autores, 2019.

Dentre os focos temáticos apresentados, identifica-se um maior número de trabalhos relacionados à organização do conhecimento e formação continuada de professores. Esses trabalhos levam à metodologia dos temas geradores para a sala de aula, buscando problemas presentes na comunidade estudada e elaborando sequências didáticas para serem desenvolvidas com alunos da educação básica. Um dos trabalhos relata uma atividade ocorrida durante a disciplina "Estágio supervisionado de Física" (T4), na qual os graduandos foram divididos em dois grupos, cada grupo deveria elaborar uma proposta didático-pedagógica; um grupo deveria elaborar a atividade baseada no referencial freiriano, os temas geradores; e o outro na abordagem Ciência-Tecnologia-Sociedade (CTS). Além de preparar tais atividades, os licenciandos ainda implementaram a proposta e elaboraram um diário reflexivo construído coletivamente. Outro trabalho que também envolveu graduandos de Física foi o Metodologia do Ensino de Física (T5), no qual os licenciandos elaboraram um minicurso dentro da perspectiva freiriana.

Cinco dos demais trabalhos (T3, T6, T10, T11 e T12) foram desenvolvidos pelo Grupo de Estudos em Abordagem Temática no Ensino de Ciências (GEATEC), que elaborou atividades embasadas no referencial freiriano em conjunto com professores da educação básica. Algumas das atividades presentes nos estudos foram implementadas pelos próprios acadêmicos participantes do grupo, enquanto outras foram elaboradas em cursos de formação continuada para professores de Ciências da rede pública. 


\section{e) Conceito freiriano}

Ao centrar-se no referencial freiriano presente em cada trabalho, é passível de observação as diferentes abordagens de um mesmo referencial que são ênfases dadas em cada estudo e acabam direcionando o olhar da pesquisa. Nos estudos investigados, identifica-se a presença de três conceitos associados à perspectiva freiriana e que possibilitaram classificar os estudos. O quadro 4 a seguir ilustra a distribuição dos estudos.

Quadro 4 - Distribuição dos estudos em relação a conceitos freirianos.

\begin{tabular}{|l|c|}
\hline \multicolumn{1}{|c|}{ Categoria- Foco temático } & Trabalho \\
\hline Comunidade & T3, T4, T5, T6, T9, T10, T11, T12 \\
\hline Diálogo & T3, T5, T7, T10 \\
\hline Autonomia estudantil & T5, T7, T10 \\
\hline
\end{tabular}

Fonte: autores, 2019.

Os temas geradores, por exemplo, que consistem na dinâmica codificaçãoproblematização-descodificação, possuem momentos nos quais se faz necessário o estudo da realidade do educando, do seu entorno social. Sendo assim, um dos conceitos presentes nos trabalhos é o de "temas geradores" que são associados à categoria "Comunidade". Os trabalhos T3, T4, T5, T6, T9, T11 e T12 relatam maior ênfase nessa fase, destacando o estudo da realidade na qual o trabalho é elaborado. O trabalho T11, por exemplo, desenvolve um estudo relacionado à qualidade dos alimentos vendidos em uma feira popular. Os autores trazem problemas presentes na comunidade, como a falta de saneamento básico, violência, doenças transmitidas por mosquitos e, entre esses problemas está a problemática da conservação dos alimentos vendidos na feira, especialmente das carnes. Ao abordar o problema conservação dos alimentos, foi possível o desenvolvimento de conceitos físicos relacionados ao calor e temperatura, assim como conceitos biológicos de microrganismos, saúde e higiene. Para outros problemas encontrados na feira, foram desenvolvidos conceitos relacionados às unidades de medida, ecologia, relações sociais, conservação e decomposição de alimentos em geral. Essas investigações caracterizam a abordagem como, aparentemente, interdisciplinar, ou, ao menos, multidisciplinar.

Outro aspecto basilar da pedagogia freiriana é o diálogo. E é por meio dele que o educando se vê reconhecido como um ser autêntico. Ele direciona o educando para sua autonomia, para o ser para si. O diálogo permite ao educando a expressão de sua realidade, portanto, é imprescindível sua presença no ambiente escolar, pois muitas vezes essa realidade, trazida pelo educando, não é totalmente abordada pelo educador no decorrer do processo de ensino-aprendizagem. Logo, uma das categorias analisadas é o "diálogo" que está relatado nos trabalhos T3, T5, T7 e T10. No estudo T3 de Solino, Sousa e Gehlen (2013), por exemplo, esse aspecto se revela no diálogo com os educandos, registrado por meio de gravações e diários de aula. O trabalho consiste na investigação chamada "Rio Cachoeira: 
que água é essa?”, a partir disso elaboraram-se uma série de atividades baseadas nos pressupostos freirianos. Entre essas atividades, e devido à limitação de carácteres imposta pelo evento, os autores escolheram a atividade "Problema do Barquinho" para ser descrita no relato. Os autores ainda ressaltam que a atividade é originalmente proposta por Carvalho e colaboradores (1998), porém, transposta ao contexto do rio da região. A atividade consiste em construir um barquinho que consiga flutuar na água carregando o maior número de peças de metal. Ao longo do processo, os autores registram os diálogos com os alunos, identificando conceitos em comum entre todos, ainda que não apresentados da maneira habitual à Física, como: massa, peso, flutuação, empuxo e características dos materiais. Além desse, tem-se o estudo T10, que será explorado na descrição da próxima categoria, na qual o diálogo trouxe ao estudo uma perspectiva além da pedagógica, o diálogo proporcionou uma dimensão social e política à atividade.

Tem-se, por fim, a categoria "Autonomia estudantil", na qual está expressa os trabalhos onde são relatados maior participação dos educandos no processo de ensino-aprendizagem, nos quais as premissas dos educandos foram reconhecidas como autenticas pelo educador. E evidente que os trabalhos desenvolveram todos os momentos aqui descritos - justamente por se tratarem de propostas freirianas - porém, devido a inúmeros fatores (preferências pessoais, peculiaridades dos educandos, tempo necessário para a completa execução da proposta), ao se desenvolver o pensamento freiriano, alguns conceitos estão mais presentes que outros, não ao ponto de se anularem, mas de se descartarem. Os estudos T5, T7 e T10 expressam essas características, são nesses trabalhos que podemos observar uma maior participação das premissas partidas dos educandos, o que tornou possível uma reflexão que os permitiu compreender sua posição como ser humano no mundo em que vive.

O trabalho T10 mostra um estudo em que a temática inicial é denominada "Lazer, Trânsito e Violência: Roubando vidas em Santa Luiza" que se encaixa nas três categorias de classificação. O trabalho visa romper a "cultura do silêncio" 11 " presente na comunidade e, para isso, utiliza-se do diálogo para a reflexão dos educandos sobre a condição em que vivem, dando voz às suas perspectivas, voltando a abordagem à visão particular de cada um. No trabalho são desenvolvidas algumas atividades relacionadas à segurança no trânsito, visto que é relatado, pelos educandos, e observado pelos pesquisadores, que os moradores da região não se atém às Normas Gerais de Circulação e Conduta, colocando em risco as próprias vidas e a vida de outros membros da comunidade. O trabalho, além disso, também explora as alternativas de lazer na comunidade, onde, segundo os autores, havia o objetivo de "reconhecer e valorizar os pontos turísticos e as riquezas naturais da comunidade, como as cachoeiras, lagoa de água cristalina, formações rochosas, grutas, etc." (MILLI, 2017, p. 7). Ao longo do estudo, que inicialmente buscava

11 Os autores ainda ressaltam a concepção em Freire, na qual a cultura do silêncio é caracterizada pela ausência de participação do conjunto da sociedade em processos decisórios. 
analisar as questões relacionadas à segurança no trânsito e no lazer da comunidade, tornou-se evidente a intimidação sofrida pelos moradores da região por parte de forças externas, beirando até a eminência da morte. A problemática maior surgiu a partir do diálogo com os educandos da região, tornando-se um novo objeto de estudo e, de acordo com os autores, "caracteriza diferentes demandas de ordem escolar, política e social” (p. 5)

\section{Consideraçóes Finais}

O estudo realizado parte da incumbência de analisar a presença da pedagogia freiriana nos estudos desenvolvidos no campo do ensino de Física. Como recorte, adotou-se a análise a partir de edições do SNEF no período de 2009-2017. Essas escolhas permitiram identificar que a temática é discutida a partir dos estudos de Demétrio Delizoicov e José A. Angotti, na perspectiva dos 3MP. O estudo, todavia, propôs-se a ir além e observar nos estudos conceitos como os de comunidade, diálogo e autonomia, que, nas revisões de literatura, não têm grande ênfase.

Nesse contexto delimitador e desafiante, identificou-se que o conceito de comunidade está entrelaçado ao de temas geradores que, por sua vez, revelam-se presentes nos estudos, envolvendo propostas didáticas pautadas nos 3MP. Outro aspecto identificado nesse estudo, foi o de que os conceitos basilares na perspectiva freiriana e mencionados anteriormente estão presentes em todos os trabalhos, contudo, em proporcionalidade diferentes, o que possibilitou a classificação nas distintas categorias.

Do analisado, observa-se que os estudos envolvendo a obra de Paulo Freire e o ensino de Física, além de estarem pautados em propostas didáticas associadas aos 3MP, estão alicerçados em discussões ligadas à obra Pedagogia do Oprimido. Pode-se observar, além disso, que o mesmo referencial é abordado com diferentes enfoques a partir da voz de quem o anuncia. Sendo assim, torna-se evidente a necessidade de estudos reflexivos que discutam o caráter freiriano das pesquisas desenvolvidas, visto que, a abordagem desse referencial está sujeita às diferentes interpretações daqueles que a utilizam. Novas pesquisas podem surgir de tal necessidade, englobando um número maior de trabalhos presentes em outros bancos de dados, ainda centrados na reflexão em torno do caráter freiriano.

\section{Referências}

ANGOTTI, José André. Solução alternativa para a formação de professores de ciências: um projeto educacional desenvolvido na Guiné-Bissau. 1982. Dissertação (Mestrado) - Universidade de São Paulo, São Paulo, 1982.

BOGDAN, Robert C.; BIKLEN, Sari Knopp. Investigação qualitativa em educação: uma introdução à teoria e aos métodos. Porto: Porto Editora, 1994.

CARVALHO, Anna Maria Pessoa de. (org). Ciências no Ensino Fundamental: o conhecimento físico. São Paulo: Scipione, 1998. 
DELIZOICOV, Demétrio. Concepção problematizadora do Ensino de Ciências na Educação Formal. 1982. Dissertação (Mestrado em Educação) - Faculdade de Educação, Universidade de São Paulo, São Paulo, 1982.

DELIZOICOV, Demétrio. Conhecimento, tensões e transições. 1991. Tese (Doutorado em Educação) - Faculdade de Educação, Universidade de São Paulo, São Paulo, 1991.

DELIZOICOV, Demétrio. Problemas e problematizações. In: PIETROCOLA, Mauricio (Org.). Ensino de Física: conteúdo, metodologia e epistemologia numa concepção integradora. Florianópolis: UFSC, 2001.

DELIZOICOV, Demétrio.; ANGOTTTI, José A.; PERNAMBUCO, Marta A. Ensino de Ciências: fundamentos e métodos. São Paulo: Cortez, 2002.

DELIZOICOV, Demétrio; ANGOTTI, José A. Física. São Paulo: Cortez, 1991.

DELIZOICOV, Demétrio; ANGOTTI, José A. Metodologia do ensino de ciências. São Paulo: Cortez, 1990.

FONSECA, Kamilla N.; MILLI, Júlio C. L.; BOMFIM, Manuela G.; ALMEIDA, Eliane dos S.; NERES, Cleilde A.; GEHLEN, Simoni T. Contribuições da Física para a conservação da carne vendida na feira do bairro de Fátima em Itabuna/BA. In SIMPÓSIO NACIONAL DE ENSINO DE FÍSICA, 22, 2017, São Carlos, SP. Anais... São Paulo: SBF.

FREIRE, Ana. Maria A. A trajetória de Paulo Freire. In: GADOTTI, Moacir. et al. (Orgs). Paulo Freire: uma biobibliográfica. São Paulo: Cortez Editora, 1996. p. 27-64

FREIRE, Paulo. Pedagogia do Oprimido. 57 ed. Rio de Janeiro: Paz e Terra, 2014.

GAMA, Leandro D.; Zanetic, João. Abordagens epistemológicas no ensino de Física: a cosmologia como tema motivador. In SIMPÓSIO NACIONAL DE ENSINO DE FÍSICA, 18, 2009, Vitória, ES. Anais... São Paulo: SBF.

GEHLEN, Simoni T.; MACHADO, Aniara; AUTH, Milton A. Freire e Vygotsky no Simpósio Nacional de Ensino de Física. In: SIMPÓSIO NACIONAL DE ENSINO DE FÍSICA, 18, 2009, Vitória. Anais... São Paulo: SBF.

GIL, Antônio C. Como elaborar projetos de pesquisa. 5. ed. São Paulo: Atlas, 2010.

HEGEL, George F. Fenomenologia do Espírito: parte I. 2. ed. Petrópolis: Vozes, 1992.

LÔBO, Igor; GOUVÊA, Guaracira. Paulo Freire e ensino de Física: o caráter freireano dos relatos de experiência apresentados do I ao XXI SNEF. In: SIMPÓSIO NACIONAL DE ENSINO DE FÍSICA, 22, 2017, São Carlos, SP. Anais... São Paulo: SBF.

MILLI, Júlio C. L.; BOMFIM, Manuela G.; FONSECA, Kamilla N.; NERES, Cleilde A.; DÓREA, Maria A. M.; SILVA, Hiago L. N.; GEHLEN, Simoni T. Os momentos pedagógicos e a análise textual discursiva na abordagem do conceito de trocas de calor 
com professores de ciências. In SIMPÓSIO NACIONAL DE ENSINO DE FÍSICA, 22, 2017, São Carlos, SP. Anais... São Paulo: SBF.

MILNITSKY, Renan; MACHADO, Yuri; GURGEL, Ivã. Quem está no centro? Um confronto epistemológico entre as visões de mundo geocêntrica e heliocêntrica. In SIMPÓSIO NACIONAL DE ENSINO DE FÍSICA, 21, 2015, Uberlândia, MG.

Anais... São Paulo: SBF.

MUENCHEN, Cristiane. A disseminação dos três momentos pedagógicos: um estudo sobre práticas docentes na região de Santa Maria-RS. 2010. Tese (Doutorado em Educação Científica e Tecnológica) - Universidade Federal de Santa Catarina, Florianópolis, 2010.

NOVELLI, Pedro G. O Conceito de educação em Hegel. Interface: comunicação, saúde, educação, v. 5, n. 9, p. 65-88, 2001.

OLIVEIRA, Leandro; GURGEL, Ivã; WATANABE, Giselle. Problematizando o aquecimento global: análise da apropriação de ideias freirianas de educação por professores. In SIMPÓSIO NACIONAL DE ENSINO DE FÍSICA, 22, 2017, São Carlos, SP. Anais... São Paulo: SBF.

ROMANOWSKI, Joana Paulin; ENS, Romilda Teodora. As pesquisas denominadas do tipo "Estado da Arte”. Diálogos Educacionais, v. 6, n. 6, p. 37-50, 2006.

SAITO, Marcia T.; GIMENES, Kathia S.; SILVA, Rodrigo C. da; RAMOS, Ismael de O.; Gurgel, Ivã. Os usos do celular: uma proposta de abordagem temática na perspectiva freiriana. In SIMPÓSIO NACIONAL DE ENSINO DE FÍSICA, 21, 2015, Uberlândia, MG. Anais... São Paulo: SBF.

SILVA, Roger M. da; SOUSA, Polliane S. de; NOVAIS, Edcleide da S. P.; FONSECA, Kamilla N.; GEHLEN, Simoni T. A organização de atividades didático-pedagógicas de Ciências baseada no tema gerador "o perigo do rio água preta em pau Brasil/BA". In SIMPÓSIO NACIONAL DE ENSINO DE FÍSICA, 21, 2015, Uberlândia, MG. Anais... São Paulo: SBF.

SOLINO, Ana P.; SOUSA, Polliane S. de; GEHLEN, Simoni T. A problematização freiriana no contexto do ensino de ciências por investigação: contribuições para o ensino de física nos anos iniciais. In SIMPÓSIO NACIONAL DE ENSINO DE FÍSICA, 20, 2013, São Paulo, SP. Anais... São Paulo: SBF.

SOUSA, Polliane S. de; SANTO, Luiz H. da S.; REIS, Yasmin A. dos; GEHLEN, Simoni T. Abordagem temática freiriana no ensino de Ciências/Física: uma experiência no Estágio Supervisionado em Física. In SIMPÓSIO NACIONAL DE ENSINO DE FÍSICA, 21, 2015, Uberlândia, MG. Anais... São Paulo: SBF.

TRIVIÑOS, Augusto Nibaldo da Silva. Introdução à pesquisa em ciências sociais: a pesquisa qualitativa em educação. São Paulo: Atlas, 1994. 